ARGONNE NATIONAL LABORATORY

P. O. Box 299

Lemont, Illinois

EFFICIENCY STUDIES OF A HIGH-EFFICIENCY, HIGH-TEMPERATURE FILTER AGAINST FRESHLY

GENERA TED URANIUM OXIDE FUME

by

Edward W. Conners, Ir.

Donald P. O'Neil

June 1954

Operated by The University of Chicago

under

Contract W-31-109-eng-38 


\section{DISCLAIMER}

This report was prepared as an account of work sponsored by an agency of the United States Government. Neither the United States Government nor any agency Thereof, nor any of their employees, makes any warranty, express or implied, or assumes any legal liability or responsibility for the accuracy, completeness, or usefulness of any information, apparatus, product, or process disclosed, or represents that its use would not infringe privately owned rights. Reference herein to any specific commercial product, process, or service by trade name, trademark, manufacturer, or otherwise does not necessarily constitute or imply its endorsement, recommendation, or favoring by the United States Government or any agency thereof. The views and opinions of authors expressed herein do not necessarily state or reflect those of the United States Government or any agency thereof. 


\section{DISCLAIMER}

Portions of this document may be illegible in electronic image products. Images are produced from the best available original document. 


\title{
EFFICIENCY STUDIES OF A HIGH-EFFICIENCY, HIGH-TEMPERATURE FILTER AGAINST FRESHLY \\ GENERATED URANIUM OXIDE FUME
}

by

Edward W. Conners, Jr.

Donald P. O'Neil

\begin{abstract}
Results of an investigation of the efficiency of a highefficiency high-temperature filter against freshly generated uranium oxide are given. Efficiencies ranged from $95.5 \%$ to $99.5 \%$ against an aerosol having a count median diameter of 0.12 micron and a geometric standard deviation of 3.29 .

Factors affecting the performance of this filter and the effect on permissible stack emissions are discussed.
\end{abstract}

I. Introduction

A. The High-Efficiency High-Temperature Filter

This filter consists of a glass-asbestos or all-glass paper pleated in the fashion of the earlier AEC filter and mounted with furnace cement in a metal frame. It was developed by $A . D$. Little, Inc., in response to a request by the AEC.(1) All the advantages of high efficiency and low resistance attributed to the standard AEC \# 1 filter have been retained in the new model with the additional asset of high-temperature $\left(>500^{\circ} \mathrm{F}\right)$ resistance.

This study was initiated in an effort to determine the efficiency of the filter against uranium oxide fume formed by combustion of uranium metal turnings. Uranium oxide fume was chosen because it is believed that its physical characteristics closely resemble those of plutonium. Inasmuch as increasing use of this type of filter material is planned, knowledge of its performance against such metal fumes is essential in order that stack emis sions be predictable and controllable. 
II. Equipment and Experimental Technique

\section{A. Equipment (Figure 1) \\ 1. Filter}

The test filter was a standard 10" $\times 10 " \times 5 \frac{1}{2} "$ all-glass media unit mounted in a metal frame having an effective filtration area of approximately $21.5 \mathrm{ft} .(2)$ It has a rated air flow of 125 cubic feet per minute.

\section{Hood}

The hood in which the uranium was burned was constructed of $\frac{1}{2}$ " plywood in the form of a box $2 \frac{1}{2} \prime^{\prime} \times 2 \frac{1}{2} \prime^{\prime} \times 2^{\prime}$ and lined with an incombustible sheet plastic. The front face was cut to permit installation of a 24 " $x 24$ " AEC filter for removal of atmospheric dust. A square port ( $\left.8 \frac{1}{2} " x 8 \frac{1}{2} "\right)$ was cut into the side of the hood through which the uranium to be burned was introduced into the hood. This port was covered during tests with a piece of Lucite and sealed with adhesive tape.

Air was drawn into the hood through the AEC filter, over the burning uranium and out through a 6" duct leading from the back of the hood to the test filter.

\section{Duct System and Filter Holder}

A 6" diameter galvanized duct connected the hood, filter holder, and blower. A Stairmand (2) disc was placed in the duct approximately 2 ' from the hood to produce turbulence and a flat velocity profile of the air at the sampling point, since more representative air samples may be obtained under these conditions.

The filter holder was also fashioned out of galvanized sheet metal in the shape of a two-piece, flanged rectangular box, 10 " $\times 11$ " $\times 14$ ", with transition sections to 6 " round on either end. The test filter (10" $\times 10^{n} \times 5^{\frac{1}{2}}$ " metal framed) was inserted into one-half of the holder and the two sections bolted together. A gasket was placed between the flanges to eliminate leakage. Pressure taps were soldered upstream and downstream of the flange as shown in Figure 2.

Sample ports were located upstream and downstream of the test filter at distances of 6'10' and 5'5" respectively.

Air flow was metered with the Willson Heated Thermometer Anemometer and regulated by means of a damper in the duct just upstream of the blower. Table $I$ lists the test air volumes and corresponding filter resistance. 


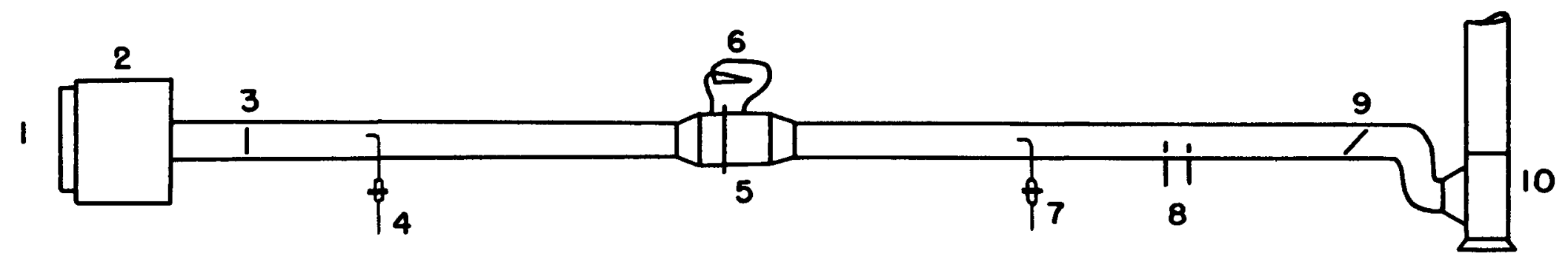

1. $2^{\prime} \times 2^{\prime} \triangle E C$ Filter

2. Plywood Hood, $2^{1 / 2^{\prime}} \times 2 \frac{1}{2^{\prime}} \times 2^{\prime}$

3. Stairmand Disk

4. Upstream Sampling Point

5. Test Filter Holder
6. Inclined Manometer

7. Downstream Sompling Point

8. Willson Heated Thermometer Anemometer

9. Flow Regulating Damper

10. Blower

Not to scale

FIGURE I.

SCHEMATIC DIAGRAM OF

TEST APPARATUS. 


\section{5}

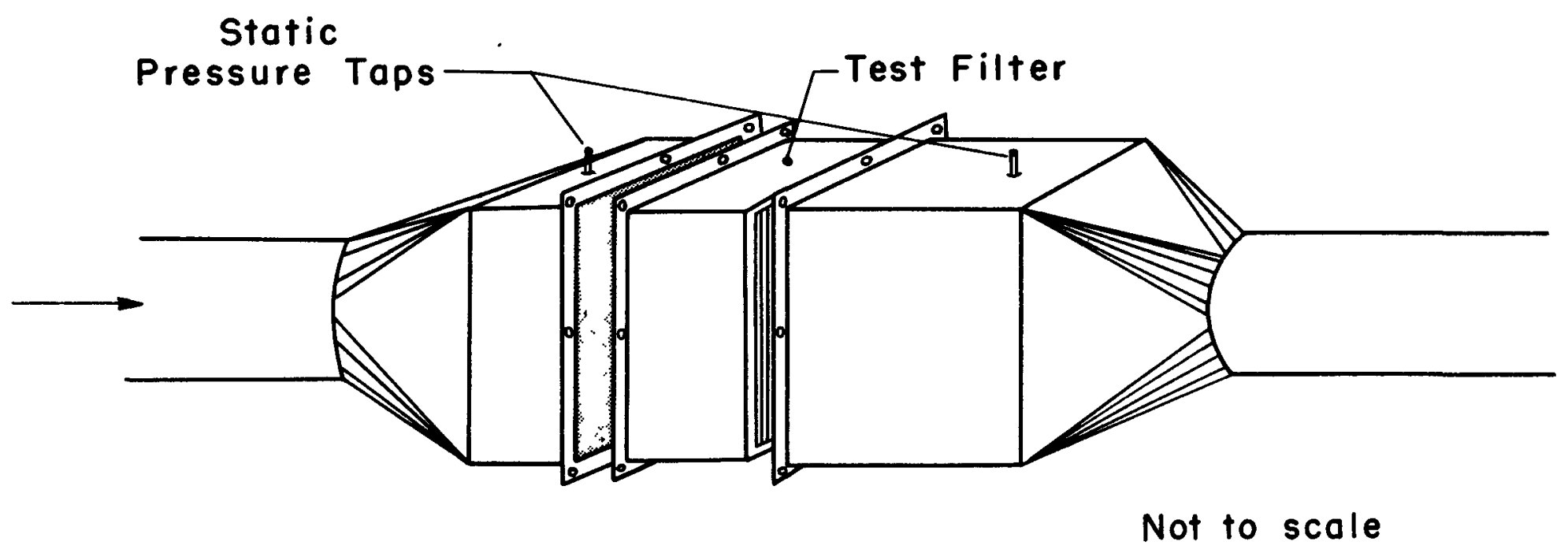

FIGURE 2.

EXPLODED SCHEMATIC DIAGRAM

OF FILTER HOLDER. 
TABLE I

\begin{tabular}{cccc} 
Air Vol. $(\mathrm{cfm})$ & $\begin{array}{c}\text { Duct } \\
\text { Velocity }\end{array}$ & $\begin{array}{c}\text { Filter Face } \\
\text { Velocity }\end{array}$ & $\Delta$ p, In. of $\mathrm{H}_{2} \mathrm{O}$ \\
\cline { 2 - 3 } 50 & 255 & 2.32 & 0.30 \\
93 & 475 & 4.32 & 0.69 \\
145 & 740 & 6.75 & 0.98 \\
170 & 870 & 7.8 & $1.23^{\prime \prime}$
\end{tabular}

The blower was a New York Blower Company Type GI, Size 14, belt-driven by a $\frac{1}{2}$-horsepower electric motor. The maximum air flow through the system with this blower was $170 \mathrm{~cm}$.

\section{Uranium Burning Apparatus}

Uranium was burned in porcelain evaporating dishes placed on a metal plate atop a tripod. The tripod was placed in the hood in line with the duct centerline at a point six inches away from the opening. Ignition of the uranium turnings was by means of a coiled piece of Nichrome resistance wire placed in the dish and connected to a rheostat located outside the hood. A small hole ( $\frac{1}{2} "$ dia.) drilled through the hood at a point near the exit duct permitted introduction of a copper tube through which air was applied, when desired, by squeeze bulb directly to the burning uranium.

\section{Sampling System}

Depending upon the purpose for which the sample was intended, two methods of sampling were utilized during the study. The first was collection on a Millipore filter (Figure 3) and the second was by means of the electrostatic precipitator (Figure 4). All samples on Millipore filters were analyzed chemically, while the precipitator samples were collected on Formvar-coated copper grids for study in the electron microscope. In each case, air was drawn from the duct through a $\frac{1}{2}$ " glass probe, directed into the airstream, and thence through the collecting agent by means of a $1-c$ fm Gast air pump. Air flow was metered by means of a rotameter. Isokinetic sampling rates were maintained for collection on the Millipore filters and on upstream samples with the electrostatic precipitator. Non-isokinetic samples were unavoidable on the downstream side of the filter in the case of the electrostatic precipitator, since the area of the grids was only a small percentage of the total collection area in the tube and permissible sampling time was short. Since the particles passing the filter were less than one micron in size, there should be little or no error resulting from this sampling procedure. 
7

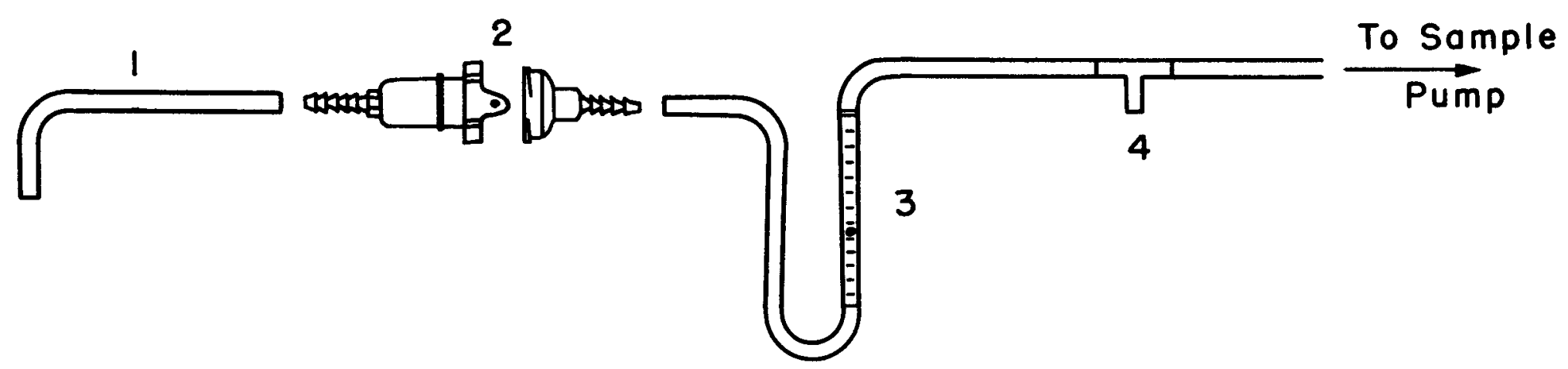

1. Glass Duct Probe, $1 / 2$ " Dia.

2. Millipore Filter Holder
3. Rotameter

4. By-Pass

FIGURE 3.

EXPLODED SCHEMATIC DIAGRAM OF SAMPLING APPARATUS. 


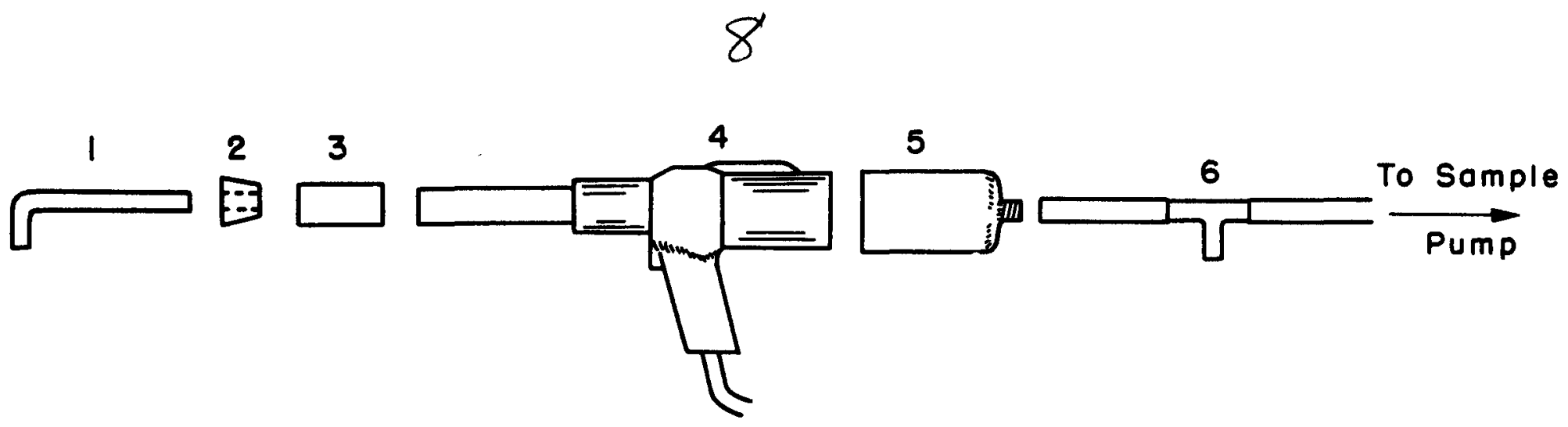

I. Glass Duct Probe, $1 / 2$ "Dio.

2. \#8 Rubber Stopper

3. Rubber Hose, I $y_{2}$ " Dia.
4. Electrostatic Precipitator

5. Polyethlene Bottle w/Bottom Removed

6. By-Pass

FIGURE 4.

EXPLODED SCHEMATIC DIAGRAM

OF SAMPLING APPARATUS. 


\section{Electron Microscope}

With the cooperation and valuable assistance of $L$. E. Roth and $O$. T. Minick of the Biological and Medical Research Division, the electron microscope was used for study of the particle size distribution of the uranium oxide upstream and downstream of the test filter.

Initially, samples for electron microscopy were mounted by dissolving portions of the Millipore filter in acetone or ethyl acetate. This technique was not satisfactory and was finally abandoned. Satisfactory results were obtained by direct collection on the electron microscope grids in the electrostatic precipitator. The sample preparation and electron microscopy will be explained in more detail in subsequent paragraphs.

\section{B. Experimental Technique}

\section{Test Procedures}

Uranium turnings were prepared by washing in trichloroethylene to remove oil and dirt. They were then air-dried. While the turnings were drying, a clean procelain evaporating dish was weighed with the resistance wire used for ignition in place. The dry uranium turnings were added and the total weight recorded. Efforts were made to choose turnings of approximately the same size, thickness, and general shape in order to promote a similar surface throughout the mass during the burning.

The dish with the turnings was placed on the metal tripod inside the hood and the wires from the rheostat were connected to the resistance wire in the dish. The loading port was then closed and taped. The air flow in the system and the corresponding resistance across the filter were recorded. Millipore filters were placed in the holders and the pumps started. The sample air flow was then adjusted to that which would produce isokinetic samples.

When the preliminary adjustments were completed, the rheostat was turned on and adjusted to approximately 20 volts. Timing of the sample began with the first visible sign of self-sustained uranium combustion and continued for the duration of active combustion. When active combustion ceased, the sample pumps and timer were also stopped.

2. Samples Analysis

a. Chemical

After the sampling was completed the Millipore filters were removed from the holders and placed in Petri dishes. They were labelled and returned to the Industrial Hygiene Laboratory for uranium 
analysis by fluorophotometric techniques. (3) Briefly, this method involves dissolution of the filter and uranium oxide in nitric acid, dilution, and drying of a small aliquot in a platinum dish. A flux of $10 \%$ sodium carbonate and $90 \%$ sodium fluoride is fused in the dish under gas heat. When cool, the fluorescence of the material under ultra-violet light is determined in the fluorophotometer and the uranium content calculated.

\section{b. Microscopic}

Many attempts were made to develop a satisfactory technique for producing an electron microscope specimen from the Millipore filter samples. The most promising techniques were those in which a small portion of the Millipore filter was placed on a microscope grid and dissolved in acetone or ethyl acetate. The particles were retained on the Formvar membrane which covered the grid.

Three variations of this procedure found in current literature $(4,5,6)$ were tried, but none was consistently satisfactory. It was found that the solvents frequently attacked the Formvar membrane or failed to dissolve all the Millipore filter, thus leaving a residue which made it impossible to obtain satisfactory electron photomicrographs. Some tendency of the particles to "flow" with the dissolving filter was also observed. Because of these difficulties, this approach was finally abandoned in favor of direct collection on the electron microscope grids in electrostatic precipitator tubes. This technique generally was satisfactory except that some tendency of the particles to collect upon the metal portions of the grid in preference to the Formvar membrane was noted. This has been observed by others using this method; however, it is not felt that any appreciable error was introduced in this manner.

Samples collected directly upon grids mounted in precipitator tubes required no further preparation but were simply placed in the specimen holder of the microscope and viewed. Satisfactory fields were photographed and enlargements made for counting and sizing. Representative electron photomicrographs of uranium oxide are shown in Figures 5, 6, and 7 .

III. Results

A. Fume Characteristics

1. Physical

Because of the nature of the combustion of the uranium turnings, it was assumed that the fume given off was the "black oxide" $\left(\mathrm{U}_{3} \mathrm{O}_{8}\right)$. This material, as seen in electron micrographs, is dense and irregularly shaped. Chemical handbooks describe it as a dark green to black solid with a specific gravity of 7.31 . 


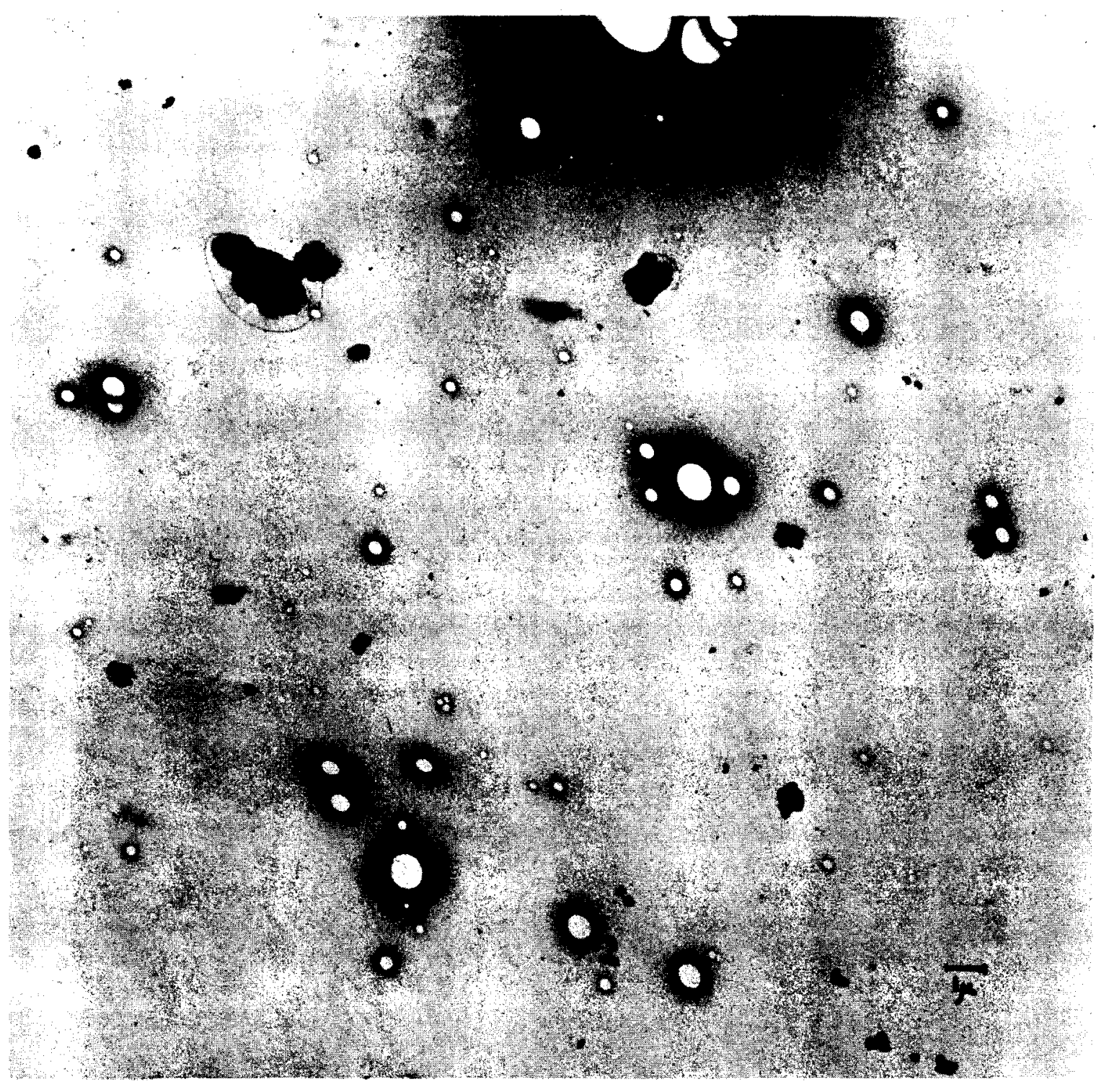

\section{Figure 5}

Electron photomicrograph of uranium oxide $6700 \mathrm{X}$. 


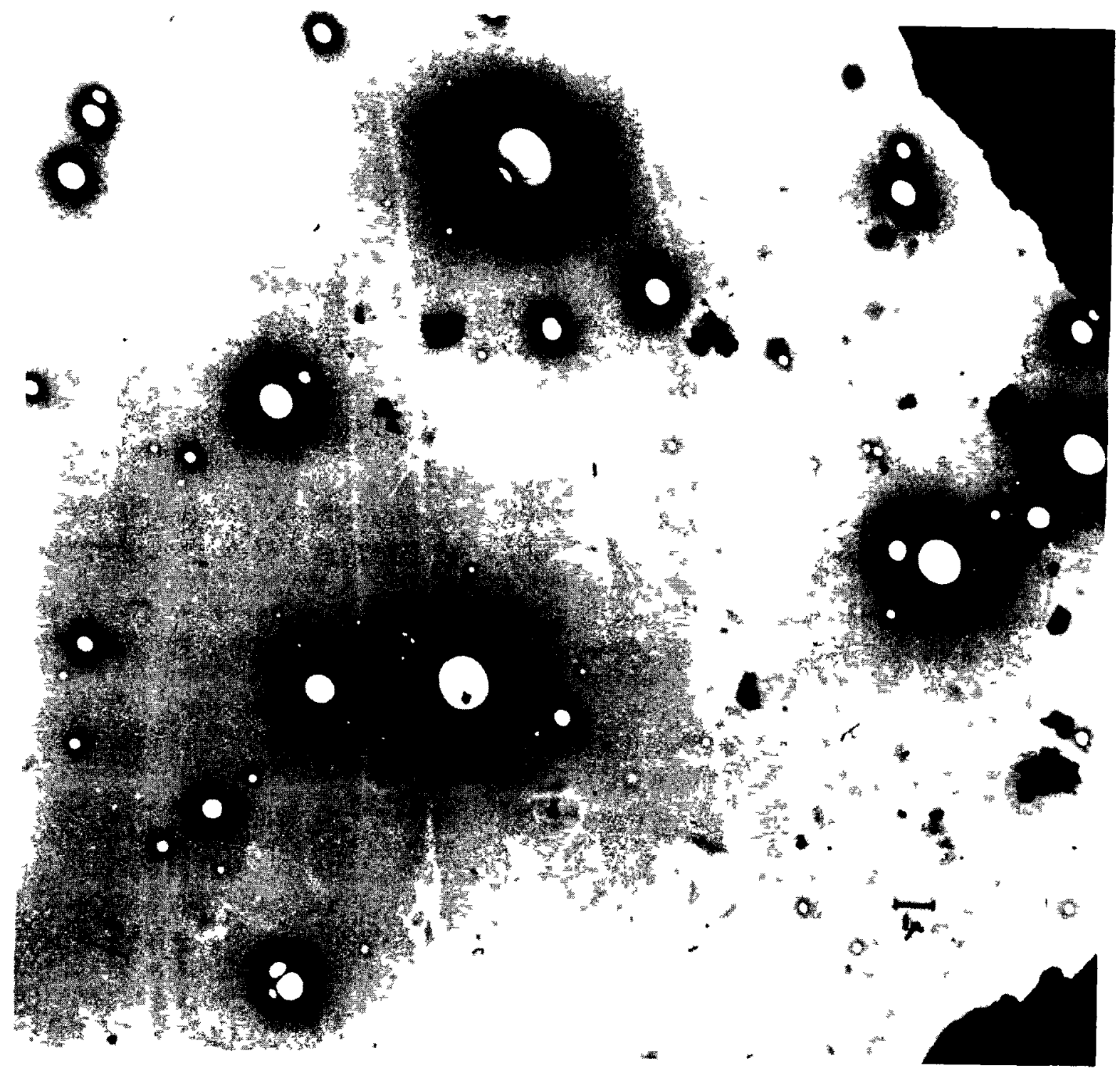

Figure 6

Electron photomicrograph of uranium oxide $6700 \mathrm{X}$. 


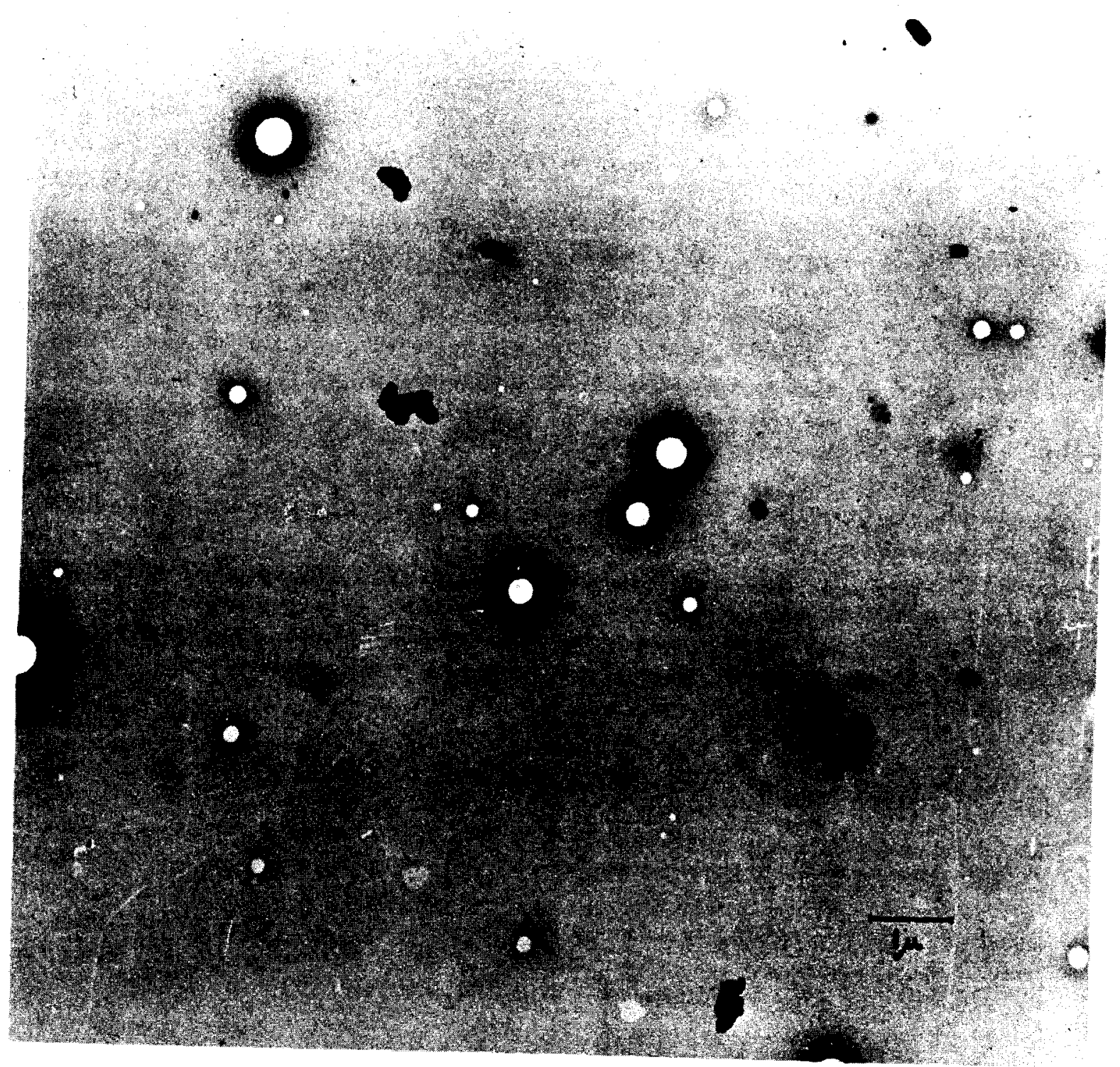

Figure 7

Electron photomicrograph of úranium oxide $15000 \mathrm{X}$. 
A study of electron micrographs showed a strong tendency toward agglommeration in the upstream sample; this made it difficult to obta in accurate data in sizes. Four hundred fifty-nine particles were sized in as nearly a random technique as possible, avoiding only obvious agglomerates, and showed a count median diameter of 0.12 micron with a geometric standard deviation of 3.29. (Figure 8)

Sizing of the downstream sample was simplified because of the absence of agglomerates. The count median diameter was 0.028 micron with a geometric standard deviation of 2.62 as determined by sizing 410 particles and extrapolating the curve to the $50 \%$ value. (Figure 8 )

\section{Quantity of Fume Airborne}

Calculations were made of the total fume in the duct at the upstream sample point in an effort to express the amount of fume getting into the exhaust system as a percentage of the original quantity of uranium burned. These computations are not exact, but rather are of order of magnitude since the quantity of uranium deposited on the ductwork and in the hood was not determined. Values ranged from $0.0004 \%$ to $0.007 \%$, although a single observation reached $0.02 \%$. The weighted mean value was $0.0026 \%$. It appears reasonable that the range of values shown are conservative, since the material burned presented a large surface area which promotes fume formation.

\section{B. Filter Efficiency \\ 1. Chemical Analysis}

Chemical analys is of the Millipore filter samples upstream and downstream of the test filter indicated efficiencies ranging from $95.5 \%$ to $99.5 \%$. The weighted mean efficiency was $96.7 \%$. In general, the efficiency increased with an increase in concentration and decreased as the filtration velocity was increased. These data were not suitable for plotting, however, because of the narrow range of concentration.

\section{Particle Size}

Comparison of the size data obtained from electron micrographs of upstream and downstream samples shows very strikingly the high efficiency of the filter against particles of $0.3-$ micron size or larger. In sizing 410 particles from downstream samples, only four particles of 0.3-micron size or larger were found for a percentage removal of approximately $99 \%$. This is in general agreement with the design criteria of $99.95 \%$ for the filter. 
The effect of this removal is shown in Figure 8 , the plot of the size distribution of upstream and downstream samples, as a reduction in count median diameter from 0.12 micron upstream to 0.028 micron downstream of the test filter.

IV. Discussion and Conclusion

A. Efficiency and Fume Concentration

In the preceding section, the results of the filter tests were summarized. Efficiencies ranged from $95.5 \%$ to $99.5 \%$ and particle size studies showed virtually complete $(99 \%)$ removal of all particles over $0.3 \mathrm{micron}$ in diameter. It is important to note that although the over-all efficiency was found to be relatively low $(96.7 \%)$, the efficiency against $0.3 \mathrm{micr}$ on approximated the design requirements. Thus, the lower overall efficiency values must result from the presence of a large number of particles less than $0.3 \mathrm{micr}$ on in the freshly generated fume.

Studies of various filter media by LaMer(7) using DOP (dioctyl phthalate) and similar aerosols indicate that, at constant velocity, collection efficiency lecreases with a decrease in particle size. Since the aerosol used in our tests displayed a wide variation in size, while the velocity for each series was constant, the individual test efficiency results were affected chiefly by the particle size distribution and concentration. Electron micrographs of the uranium oxide generated in these tests showed a count median diameter of 0.12 micron. By definition, $50 \%$ of the particles are equal to or less than this size, and, according to LaMer's studies, this high proportion of very small particles would be expected to result in a lower filter efficiency because of failure to collect many of the small particles.

LaMer's data also show the penetration by small particles to be greater at high velocities than at low velocities.

In general, the results of our studies may be interpreted as being in agreement with LaMer's findings as evidenced by the large numbers of particles of less than 0.15 micron passing the filter.

This could lead to very serious consequences in event of free combustion of uranium or plutonium if all the metal burned were discharged into the atmosphere as a fume. Fortunately, only a small percentage of the metal becomes airborne as fume, and this concentration is reduced considerably by deposition on cold surfaces. Agglomeration further eliminates much of the fume through formation of large, readily filterable particles.

Our studies showed a weighted mean percentage of fume reaching the sampling point of $0.0026 \%$ of the initial charge. The location of the sampling point (approximately one-half the distance between the burning 


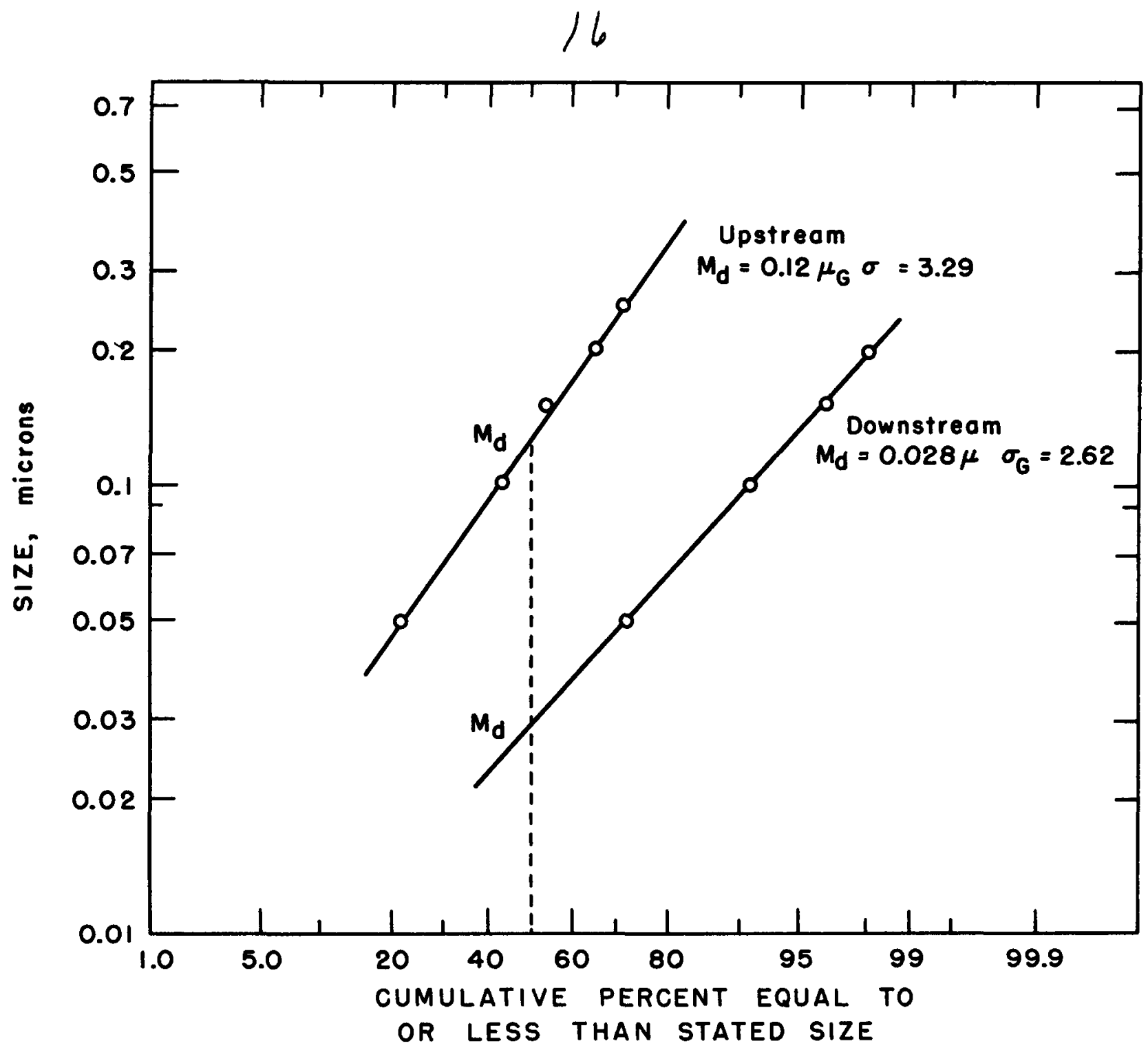

FIGURE 8.

2 
uranium and the filter) gives rise to the suggestion that a somewhat greater reduction in fume concentration might be observed before the filter was reached. This removal phenomenon, however, reaches a point of diminishing return as the result of decreased concentration of fume in the duct caused by the settling out of large agglomerates and deposition upon the duct. Naturally, fewer particles in suspension means a smaller probability of contact and particle growth. We do not know where this point may be, but it is likely that the maximum losses have occurred by the time the air and fume have traveled sufficiently far to become cool.

Other factors affecting fume concentration are: (1) quantity and surface area of burning material; for example, 10 grams of fine lathe turnings would burn more violently and thus liberate more fume than a . 10 -gram block of the same material burning under the same conditions, and (2) volume and velocity of air passing over and/or through the burning material. An air jet, for example, causes a more violent burning action with a resultant higher fume concentration than would general air movement through the hood and across the dish. Efficiency varies directly with the concentration of fume and the preceding factors indicate that the variance in efficiency found in these studies is in part attributable to the variation in concentration which was not subject to control.

\section{B. Filter}

It was observed that the filter media showed cracks running along the edge of each pleat in the surface. There was no evidence that the cracks extended through the material and filter resistance measurements showed no drop below rated resistance. Studies by LaMer, however, indicate that "pinholes" may exist in a filter media and permit passage of appreciable amounts of aerosol with little change in resistance. This phenomenon has been explained by Knudson and White ${ }^{(8)}$ as being the result of an increase in turbulence about the hole with a local high resistance resulting. Thus, it is entirely possible that the comparatively low over-all efficiency $(96.7 \%)$ may also be due in part to "pinholes" in the filter material which permitted large numbers of particles to pass.

Presence of cracks in the bonding cement of other filters of the same type in stock has also been observed although the test filters did not display this fault. These cracks would naturally have an adverse effect on filtration efficiency.

\section{Effect on Stack Emission}

Inasmuch as this týpe of filter is intended for use as the final clean-up filter and generally will not be followed by any other type of air cleaner, the amount of contaminant discharged from the stack is dependent upon the efficiency of the filter. This problem may be approached by 
considering a maximum permissible level of concentration of contaminant in the atmosphere and applying factors of dilution, wind velocity, volume of exhaust air, height of stack, efficiency of filter, and percentage of fume generated. Such an approach was used by Hilst and Moses (9) of Argonne and their calculations indicated that as much as 2 milligrams of plutonium could be discharged from an 85-foot stack over a period of 5 minutes at $5000 \mathrm{cfm}$ air flow with little likelihood of anyone receiving an excessive exposure. Application of the percentage values for fume emission and filter efficiency as determined in this study shows that a stack discharge of 2 milligrams would necessitate combustion of approximately 2.5 kilograms of plutonium.

In general, it appears that the fume emission percentage, filter efficiency, and stack height combine to make the possibility of a dangerously high ground concentration remote.

\section{Conclusions}

The results of these studies are offered as a guide in evaluating the potential uses of this filter in filtering process air from plutonium work including the products of combustion if the assumption is made that the behavior of plutonium upon combustion is similar to that of uranium in quantity and size distribution of fume liberated. It is felt that this filter will prove satisfactory for such uses even though the efficiency against freshly generated uranium oxide was slightly below that generally expected from this type of filter. As stated in the preceding section, with the filter efficiency and fume generation expected, up to $2.5 \mathrm{~kg}$, of plutonium could be consumed with no excessive exposures resulting. Prompt removal of chips, turnings, and other finely divided forms before appreciable amounts can accumulate will make this event a very remote possibility.

\section{ACKNOWLEDGEMENTS}

The authors wish to acknowledge with gratitude the assistance of G. C. King in the construction of the test equipment and performance of the tests, Colette C. Koehl and T. L. Duffy in performing the necessary analytical work, and the valuable constructive criticisms and suggestions of J. F. Ege, Jr. 


\section{REFERENCES}

1. "Development of a High Temperature - High Efficiency Air Filter,"

A. D. Little, Inc., NYO-4527 (August 18, 1953)

2. Anonymous (Stairmand, C. J.), Engineering (London) 152:1 Y1, 181 (1941).

3. "Fluorophotometric Determination of Uranium," G. R. Price, R. J. Ferretti, and Samuel Schwartz, Anal. Chem. 25: 322 (1953).

4. "Absolute Method of Sampling and Measurement of Solid Airborne Particulates," David A. Fraser, Arch. of Ind. Hyg, and Acc. Med., (November 1953).

5. "Preparation of Aerosols for Electron Microscopy," Ernest H. Kalmus, J. App. Phys., (January 1954).

6. "Air Cleaning Studies, Progress Report February 1, 1951 to June 30 , 1952," First, Silverman, et al., Air Cleaning Laboratory, Harvard University, NYO-1586.

7. "Studies on Filtration of Monodisperse Aerosols," V. K. LaMer, NYO-512 (March 31, 1951).

8. Naval Research Laboratory Report No. P-2642 (1945), Knudson, H. W., and L. White.

9. Private Communication. 